\title{
Changing Workplace Concepts
}

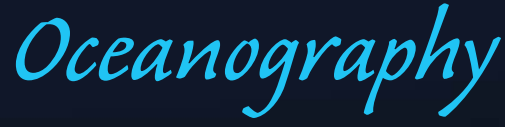

https://tos.org/oceanography

UPCOMING

SPECIAL ISSUES

DECEMBER 2021

Oceans Across the Solar System

DECEMBER 2021 SUPPLEMENT

Ocean Observing

MARCH 2022

The Changing Arctic Ocean

MARCH 2022 SUPPLEMENT

New Frontiers in Ocean

Exploration

SEPTEMBER 2022

Building Diversity and Inclusion

in the Ocean Sciences

\section{CALL FOR IDEAS!}

Do you have an idea for a special issue of Oceanography? Please send your suggestions to Editor Ellen Kappel at ekappel@geo-prose.com.
AS I'VE QUIPPED more than a few times to colleagues over the past year-and-ahalf of COVID-19 restrictions, I've been practicing for a pandemic for more than 20 years. I am all too familiar with the pros and cons of working from home over extended periods. I was a pioneer in that arena, starting in the days (about 1999) when using a modem and my home telephone line to dial into the Internet was a technology breakthrough. I couldn't have started my at-home business without that outside link to the world and a way to exchange digital files with my designer, who had moved to the other side of the continent. But, even with the blistering speed that fiber-optic cabling now provides for efficiently exchanging ever larger files between us (we still work together and we still live far away from each other), I appreciate more than most the value of working face-to-face daily with colleagues.

Years ago when I was a program manager for the Ocean Drilling Programs at Joint Oceanographic Institutions, working from home was not part of the workplace lexicon. I recall discussions among the top managers about letting some staff "telecommute," but they decided that being in the office was necessary for staff interactions, many of them spontaneous, that improve work outcomes, and there was some concern that morale would suffer if not all staff had the option of telecommuting at least some of the time. And to be frank, there was concern about how much work would really get done if people stayed home. There were no data yet on the productivity of telecommuters.

Fast forward to the COVID-19 pandemic of 2020-2021, when many nonessential workers had to find ways to get their work done from home. For some jobs in the business world, and for some age groups, it was a relatively easy adjustment. For others, such as researchers whose fieldwork or experiments were canceled or postponed or those who had children at home, not so much. Many people whose office work relied on digital files that could be accessed over the Internet found that they could be productive workers from home and surely did not miss the time consumed by commuting to work. Zoom and similar technologies allowed staff meetings to continue to take place, and we all got better at it with more experience. Large conferences experimented with novel ways to run sessions, promote exchange of knowledge, and foster networking, even if remotely. The availability of online webinars exploded, substantially increasing access to a wide array of learning opportunities-a trend I hope continues.

As businesses, institutions, and governments look at new workplace models for the future, my hope is that people who work in those sectors will mostly choose to go back to the office, at least for the majority of the work week. For young workers to grow in their careers, they need to work side-by-side with more experienced mentors, and mentors need to be able to work one-on-one with the next generation. Ensuring a knowledgeable, vibrant, and savvy workforce requires interacting with people on a regular basis-in person. While it is enticing to make the choice to work from home if that option is available-I can't deny the benefits of having the freedom to throw in a load of laundry, run errands, or go to the gym when I feel like it-all in all, the office is the better place to be.

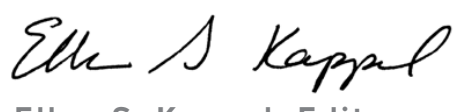

Ellen S. Kappel, Editor 